\title{
Short Interfering RNA (siRNA) based Medicines and the Future of RNAi Therapy: A Mini Review
}

\author{
Valle ABCS, Gualberto ACM and Pittella F* \\ Federal University of Juiz de Fora, Brazil \\ Submission: March 06, 2020; Published: April 08, 2020 \\ *Corresponding author: Pittella F, Federal University of Juiz de Fora, Brazil
}

\begin{abstract}
After twenty years of short interfering RNA (siRNA) research, RNA interference (RNAi)-based medicines are emerging as a novel class of drugs since the recent approval of Onpattro ${ }^{\circledR}$ and Givlaari ${ }^{\circledR}$ by the Food and Drug Administration (FDA). RNAi is a post-transcriptional gene regulatory process in which one of its molecular effectors is a silencing inducer: the siRNA. Since the description of this pathway, several research groups are searching for therapeutic applications of siRNA against diseases with overexpressed genes. Many challenges came across and strategies to improve siRNA stability and delivery were developed. Nevertheless, higher efficacy, safety and successful delivery are still some of the challenges to be overcome. In this mini review, we are presenting some of the biological barriers for effective siRNA delivery as well as an update of the current progress in RNAi-based medicines in phase III clinical trials.
\end{abstract}

Keywords: RNA interference; siRNA; RNAi-based medicines; Delivery systems; Nanoparticles

Abbreviation: ECM: Extracellular Matrix; SiRNA: Small Interfering RNA; DS: Delivery system; RISC: RNA-Induced Silencing Complex; mRNA: Messenger RNA

\section{Introduction}

The RNA interference (RNAi) phenomenon is responsible for post-transcriptional gene silencing and was firstly reported by Andrew Fire and Craig Mello in the nematode Caenorhabditis elegans in 1998 [1]. The signaling pathway and protein complexes involved were described and the short interfering RNA (siRNA), a small double-stranded molecule, was indicated as the RNAi silencing inducer [2].

After the cleavage of long double strand RNA (dsRNA), siRNAs are produced, and it is complexed into the RNA-induced silencing complex (RISC) [2]. The main protein of this complex, Argonaute-2 (Ago2), unwinds the siRNA and cleaves the passenger strand of the siRNA, so the guide strand with other proteins forms the activated RISC complex [3]. Activated-RISC complex is then able to search for the messenger RNA (mRNA) with the exact matching sequence of the guide strand and to cleave this mRNA [4]. As a result, the protein is not produced, and the gene is silenced.

The potential therapeutic applications of the siRNA molecule and the RNAi effect are the main reasons for its tireless research. This is due to the versatility of application of this molecule that can be designed to silence virtually any overexpressed gene related to a specific disease. In addition, it can be used to block proteins that are hard to reach by conventional drugs [5]. Almost two decades passed from the discovery of the pathways and only recently RNAi-based medicines are coming to clinics.

Unlike Fire \& Mello [1], who injected a long double- and single-stranded RNA into C. elegans, Elbashir and co-workers [2] introduced synthetic siRNA and observed successful sequencespecific gene silencing in mammalian cells. This report was the first step into therapeutic applications of siRNA against several diseases [3].

\section{Current Challenges}

Although the application of siRNA therapy is promising, the research groups found many challenges in the early years (Figure 1). Examples of this are the characteristics inherent of the siRNA molecules (charge and size), nuclease susceptibility of free siRNA, dose-limiting toxicities, renal ad reticuloendothelial clearance, poor bioavailability and selectivity of target cells, insufficient therapeutic efficacy, efficient delivery, successful escape from the endosome and RNAi effect $[6,7]$.

Despite these challenges, several research groups and pharmaceutical companies looked for the improvement of these characteristics by efficient design of the siRNA molecule, by chemical modifications of the molecule or by improving the siRNA 
delivery by using nanotechnology. For the last one, the siRNA may be encapsulated or conjugated with nanometer sized delivery agents that are rationally designed to overcome delivery hurdles [7].

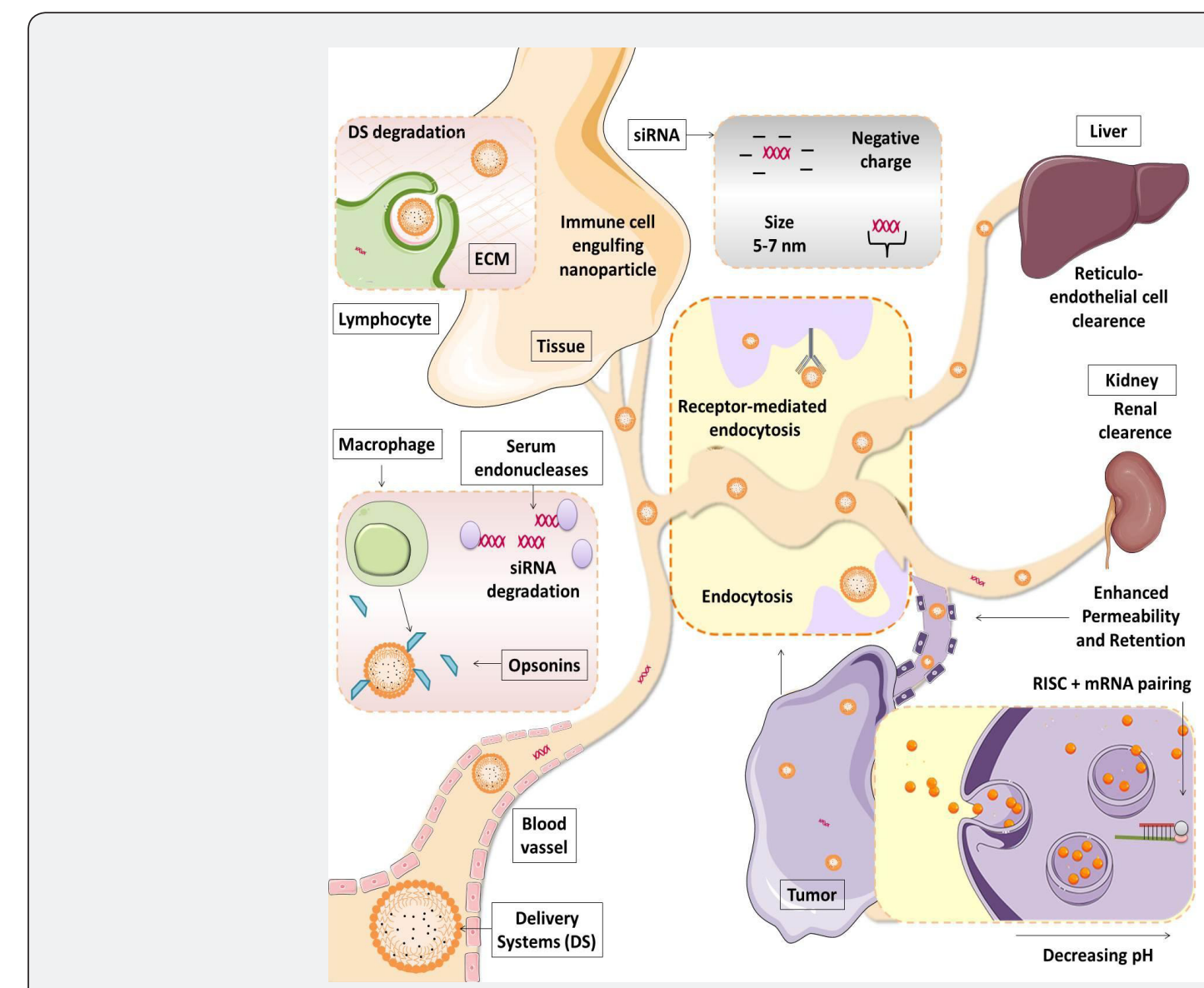

Figure 1: Biological barriers faced by siRNA and delivery systems towards RNAi therapy.

Representation of the challenges found by naked siRNA and other delivery systems after intravenous delivery. During the blood circulation, delivery system and siRNA degradation can occur after opsonin-mediated phagocytosis, serum endonucleases, immune cell engulfing and by entrapment in the extracellular matrix (ECM). The clearance may occur through the liver and kidneys, by reticuloendothelial cell and renal clearance, respectively. However, due to the enhanced permeability and retention effect, delivery systems are preferentially trafficked to tumors. This can also occur by receptor-mediated endocytosis. Once inside tumor cells, the delivery system has to escape from the endosome before lysosome degradation so the siRNA can undergo RISC incorporation to promote the desirable RNAi effect.

ECM: extracellular matrix. SiRNA: Small interfering RNA. DS: delivery system. RISC: RNA-induced silencing complex. mRNA: messenger RNA.

Nanoparticles are the main transfecting agents encapsulating siRNA. Different types of nanoparticles that are studied to deliver siRNA to target cells or organs, and it include metallic, hybrid, polymeric and lipid nanostructures, among others. They are extensively tested for efficient delivery and can have surface modification for enhanced accumulation to target tissue. Besides encapsulation, the conjugation of the siRNA with certain molecules can also promote target specificity and allow the RNAi effect, such as aptamers, amino acids and peptides [8]. This mini review will update the progress in RNAi-based medicine that uses siRNA as therapeutic agent.

\section{Current Progress of Rnai-Based Medicines}

Table 1 shows the siRNA-based drugs that are in phase III clinical trials or approved by FDA [23] up to date. It is possible to organize them in groups according to the delivery strategy: chemically modified siRNA, GaINAc (polypeptide N-acetylgalactosaminyl-transferase) conjugation and nanoparticles.

The first siRNA drug tested systemically in patients was QPI-1002 (I5NP) composed of naked siRNA for the treatment of the acute kidney injury and delayed graft function [9]. This drug completed clinical phase III trials relating prevention and reduction in severity of delayed graft function in recipients of an older donor kidney transplant [10]. QPI-1007 also completed clinical phase III and it is a neuroprotective drug for non-arteritic anterior ischemic optic neuropathy (NAION) targeting the caspase 2 gene. This experimental drug is chemically modified siRNA and the modifications within this molecule allow higher specificity, nuclease stability and attenuation of off-target effects [11]. 
Table 1: RNAi-based therapeutic drugs.

\begin{tabular}{|c|c|c|c|c|c|}
\hline $\begin{array}{l}\text { Therapeutic } \\
\text { Name }\end{array}$ & Target & Indication & Delivery System & Company & $\begin{array}{l}\text { FDA Approval } \\
\text { Date }\end{array}$ \\
\hline \multicolumn{6}{|c|}{ Commercially available } \\
\hline $\begin{array}{l}\text { Patisiran ONPAT- } \\
\text { TRO }^{\circledR} \\
\end{array}$ & TTR & Polyneuropathy after (hATTR) & Liposome & $\begin{array}{l}\text { Alnylam Pharmaceu- } \\
\text { ticals }\end{array}$ & August 2018 \\
\hline $\begin{array}{l}\text { Givosiran } \\
\text { GIVLAARI }{ }^{\circledR}\end{array}$ & ALAS-1 & Acute intermittent porphyria & $\begin{array}{l}\text { GaINAc-siRNA conjugate } \\
\text { (ESC) }\end{array}$ & $\begin{array}{l}\text { Alnylam Pharmaceu- } \\
\text { ticals }\end{array}$ & $\begin{array}{l}\text { November } \\
2019\end{array}$ \\
\hline \multicolumn{6}{|c|}{ Phase III completed } \\
\hline Lumasiran & HA01 & Primary hyperoxaluria type 1 (PH1) & $\begin{array}{l}\text { GaINAc-siRNA conjugate } \\
\text { (ESC) }\end{array}$ & $\begin{array}{l}\text { Alnylam Pharmaceu- } \\
\text { ticals }\end{array}$ & - \\
\hline Inclisiran & PCSK9 & Hypercholesterolemia & $\begin{array}{l}\text { GaINAc-siRNA conjugate } \\
\text { (ESC) }\end{array}$ & $\begin{array}{l}\text { Alnylam Pharmaceu- } \\
\text { ticals }\end{array}$ & - \\
\hline Tivanisiran & TRPV1 & Ocular pain, dry eye & $\begin{array}{l}\text { Chemically modified } \\
\text { siRNA }\end{array}$ & Sylentis, S.A. & - \\
\hline QPI-1002 (15PN) & p53 & Delayed graft function & $\begin{array}{l}\text { Chemically modified } \\
\text { siRNA }\end{array}$ & $\begin{array}{c}\text { Quark } \\
\text { Pharmaceuticals }\end{array}$ & - \\
\hline QPI-1007 & Caspase 2 & $\begin{array}{c}\text { Nonarteritic anterior ischemic optic } \\
\text { neuropathy }\end{array}$ & $\begin{array}{l}\text { Chemically modified } \\
\text { siRNA }\end{array}$ & $\begin{array}{c}\text { Quark } \\
\text { Pharmaceuticals }\end{array}$ & - \\
\hline \multicolumn{6}{|c|}{ Phase III } \\
\hline QPI-1002 (15PN) & p53 & $\begin{array}{l}\text { Prevention of MAKE at high risk for AKI } \\
\text { after cardiac surgery }\end{array}$ & $\begin{array}{l}\text { Chemically modified } \\
\text { siRNA }\end{array}$ & $\begin{array}{c}\text { Quark } \\
\text { Pharmaceuticals }\end{array}$ & - \\
\hline \multirow{5}{*}{ Fitusiran } & \multirow{5}{*}{ Thrombin } & $\begin{array}{l}\text { Severe Hemophilia A and B with inhib- } \\
\text { itors }\end{array}$ & \multirow{5}{*}{$\begin{array}{l}\text { GaINAc-siRNA conjugate } \\
\text { (ESC) }\end{array}$} & \multirow{5}{*}{$\begin{array}{l}\text { Alnylam Pharmaceu- } \\
\text { ticals }\end{array}$} & - \\
\hline & & $\begin{array}{l}\text { Severe Hemophilia A and B without } \\
\text { inhibitors }\end{array}$ & & & - \\
\hline & & $\begin{array}{l}\text { Severe Hemophilia A and B previously } \\
\text { receiving factor or bypassing agent } \\
\text { prophylaxis }\end{array}$ & & & - \\
\hline & & $\begin{array}{l}\text { Hemophilia A and B with or without } \\
\text { inhibitory antibodies to Factor VIII or IX }\end{array}$ & & & - \\
\hline & & $\begin{array}{l}\text { Prophylaxis in male pediatric with Hemo- } \\
\text { philia A and B }\end{array}$ & & & - \\
\hline \multirow{2}{*}{ Vutrisiran } & \multirow{2}{*}{ TTR } & Cardiomyopathy related to hATTR & \multirow{2}{*}{$\begin{array}{l}\text { GaINAc-siRNA conjugate } \\
\text { (ESC) }\end{array}$} & \multirow{2}{*}{$\begin{array}{l}\text { Alnylam Pharmaceu- } \\
\text { ticals }\end{array}$} & - \\
\hline & & hATTR comparing to patirisan treatment & & & \\
\hline \multirow{3}{*}{ Patisiran } & \multirow{3}{*}{ TTR } & Cardiomyopathy related to hATTR & \multirow{3}{*}{ Liposome } & \multirow{3}{*}{$\begin{array}{l}\text { Alnylam Pharmaceu- } \\
\text { ticals }\end{array}$} & - \\
\hline & & Disease progression after liver transplant & & & - \\
\hline & & Amyloidosis: re-treatment & & & \\
\hline Givosiran & ALAS-1 & Acute hepatic porphyria (AHP) & $\begin{array}{l}\text { GaINAc-siRNA conjugate } \\
\text { (ESC) }\end{array}$ & $\begin{array}{l}\text { Alnylam Pharmaceu- } \\
\text { ticals }\end{array}$ & - \\
\hline \multirow{3}{*}{ Lumasiran } & \multirow{3}{*}{ HA01 } & $\begin{array}{c}\text { Primary hyperoxaluria and primary } \\
\text { hyperoxaluria and type } 1 \text { (PH1): infants } \\
\text { and young children }\end{array}$ & \multirow{3}{*}{$\begin{array}{c}\text { GaINAc-siRNA conjugate } \\
\text { (ESC) }\end{array}$} & \multirow{3}{*}{$\begin{array}{l}\text { Alnylam Pharmaceu- } \\
\text { ticals }\end{array}$} & - \\
\hline & & $\begin{array}{l}\text { Advanced primary hyperoxaluria and } \\
\text { primary hyperoxaluria type } 1 \text { (PH1) }\end{array}$ & & & - \\
\hline & & $\begin{array}{l}\text { Primary hyperoxaluria type } 1 \text { (PH1): } \\
\text { children and adults }\end{array}$ & & & - \\
\hline
\end{tabular}




\begin{tabular}{|c|c|c|c|c|c|}
\hline \multirow{5}{*}{ Inclisiran } & \multirow{5}{*}{ PCSK9 } & $\begin{array}{l}\text { Atherosclerotic Cardiovascular (CV) } \\
\text { Disease and Hypercholesterolemia }\end{array}$ & \multirow{5}{*}{$\begin{array}{l}\text { GaINAc-siRNA conjugate } \\
\text { (ESC) }\end{array}$} & \multirow{5}{*}{$\begin{array}{l}\text { Alnylam Pharmaceu- } \\
\text { ticals }\end{array}$} & - \\
\hline & & $\begin{array}{l}\text { Hypercholesterolemia in Subjects with } \\
\text { Heterozygous Familial Hypercholester- } \\
\text { olemia }\end{array}$ & & & - \\
\hline & & $\begin{array}{l}\text { Assess effect of long-term dosing of in- } \\
\text { clisiran in subjects with high CV risk and } \\
\text { elevated LDL-C }\end{array}$ & & & - \\
\hline & & $\begin{array}{l}\text { Assess effect of Inclisiran on clinical out- } \\
\text { comes among people with CV disease }\end{array}$ & & & 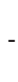 \\
\hline & & $\begin{array}{c}\text { Patients with Heterozygous Familial } \\
\text { Hypercholesterolemia }\end{array}$ & & & 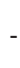 \\
\hline
\end{tabular}

ALAS 1: aminolevulinic acid synthase 1. AKI: acute kidney injury. CV: cardiovascular. ESC: enhanced stabilization chemistry. hATTR: hereditary Transthyretin-mediated amyloidosis. HA01: hydroxyacid oxidase 1. GalNAc: n-acetylgalactosamine. LDL-C: LDL cholesterol. MAKE: major adverse kidney events. PCSK9: proprotein convertase subtilisin/kexin type 9. P53: tumor protein p53. SiRNA: short interfering RNA. TRPV1: transient receptor potential cation channel subfamily $\mathrm{V}$ member 1 . TTR: transthyretin.

Another drug that completed phase III clinical trials is tivanisiran, from the company Sylents. The aim of this drug is to silence the mRNA of member 1 (TRPV1) of subfamily $V$ of the potential cation channel of the transient receptor (TRPV1) for treatment of dry eye disease. The results showed that tivanisiran significantly improved eye pain and conjunctival hyperemia in patients with dry eye and safety [12].

Other delivery strategy used by many companies is the conjugation of siRNA with certain molecules, such as GaINAc, an amino sugar derivative from galactose. This molecule binds to the asialoglycoprotein receptor (ASGPR) that is predominantly expressed on liver hepatocytes [13]. Fitusiran, inclisiran and vutrisiran are examples of this conjugated siRNA drugs in phase III clinical trials.

Hypercholesterolemia is a major cause of cardiovascular disease. Proprotein convertase subtilisin/kexin type 9 (PCSK9), a circulating protein of low abundance with an excessive effect on the regulation of plasma cholesterol levels, was a major discovery. Currently, two monoclonal antibodies, evolocumab and alirocumab, represent the first two human monoclonal antibodies fully approved by the Food and Drug Administration (FDA) that target PCSK9 and are the main treatment. Inclisiran, however, is a PCSK9-specific siRNA that prevents translation of the PCSK9 messenger RNA, leading to decreased protein concentrations and lower concentrations of LDL cholesterol. Besides that, impressive data on the safety and efficacy of inclisiran was observed in completed clinical phase 3 [15].

Fitusiran uses the RNA interference mechanism to knockdown the endogenous anticoagulant antithrombin gene. The therapeutic hypothesis is based on the fact that hemophilia $\mathrm{A}$ and $B$ are essentially disorders caused by thrombin deficiency. The knockdown of this gene significantly decreased the annualized bleeding rates in patients with hemophilia with and without inhibitors [14].
Another GaINAc-conjugated siRNA drug still in phase III of clinical trials is vutrisiran. This medication is involved in the treatment of transthyretin-mediated amyloidosis (ATTR). It acts by inhibiting the production of disease-causing TTR proteins, leading to a reduction in TTR levels [16].

In addition to the GaINAc-conjugated siRNA drugs presented so far, lumasiran has also completed phase III of clinical trials and has been submitted for FDA approval. This is a formulation that treats the type 1 primary hyperoxaluria (PH1) condition, which is a rare, life-threatening disease that can cause serious damage to kidneys and progressively to other organs. It is characterized by the pathologic overproduction of oxalate by the liver. Currently, the only curative treatment is a liver transplant, to correct the metabolic defect, combined with a kidney transplant, to replace the terminally damaged kidneys. This shows how important another solution is needed for the treatment of this disease. Promising and safe results of the phase III studies were obtained [17].

Due to urgent need of new drugs, patisiran, fitusiran, vutrisiran, lumasiran, inclisiran, givosiran and QPI-1002 (15PN) are again on phase III clinical trials to treat specific variations of the initial conditions for which they were developed.

Recently approved by FDA in November of 2019, givosiran (Givlaari ${ }^{\circledR}$ ) is the first aminolevulinic acid synthase 1 (ALAS 1) targeting RNAi drug indicated for the treatment of acute hepatic porphyria (AHP). Developed by Alnylam Pharmaceuticals group, the drug is the world's first approved RNAi therapeutic based on the company's Enhanced Stabilization Chemistry (ESC)-GalNAc conjugate technology and significantly reduced the episodes of porphyria attacks $[18,19]$.

In 2018, the Alnylam company developed Onpattro ${ }^{\circledR}$ (patisiran), the first RNAi-based drug approved by the FDA. Besides that, the same formulation is under evaluation in Canada 
and Japan. The National Health Surveillance Agency (ANVISA) approved Onpattro ${ }^{\circledR}$ in Brazil in February 2020.

Onpattro ${ }^{\circledR}$ is the only RNAi based medicine with a nanoparticle delivery strategy up to the present. It is a liposome formulation composed of $\mathrm{pH}$ sensitivity. Hereditary transthyretin-mediated amyloidosis (hATTR) is an autosomal dominant disorder characterized by the deposition of an abnormal form of the protein TTR. This frequently occurs in the peripheral nervous system (giving rise to peripheral neuropathy), but also in other organs and tissues such as the heart (which leads to cardiomyopathy), eyes, gastrointestinal tract and kidneys. RNAi therapy works to reverse the disease progression by reducing the production of altered forms of the TTR protein [20,21].

According to ClinicalTrials.gov, besides phase III clinical trials presented in the Table 1, there are 2 phase 1 and 5 phase 2 clinical trials currently in progress relating RNAi therapeutics.

\section{Future of Rnai Therapy}

Since the report of the mechanisms behind the RNA interference phenomenon, many groups and companies searched for strategies to apply RNAi into silencing overexpressed genes responsible for several diseases. In 2018, Onpattro ${ }^{\circledR}$ was the first RNAi-based medicine approved by the FDA, and opened doors for a new class of medicines. In 2019, FDA also approved Givlaari ${ }^{\circledR}$ and other RNAi-based drugs have already completed phase 3 and are waiting for FDA approval $[22,23]$.

Thus, targeted therapies achieved many positive results However, higher efficacy, safety and delivery, with minimal toxicity, immunogenicity and off-target effects are still critical issues for RNAi therapy. Despite the challenges, many strategies are being developed to surpass siRNA limitations and to promote the desired RNAi effect. Thus, great progress has been made regarding these limitations and several drugs are already in phase III of clinical trials with great results, since many of them are found to be safe and efficient.

There is plenty of room to new developments on RNAi-based medicines. Virtually, every pathological gene can be silenced using synthetic siRNA. For that, scientists can design siRNA sequences by taking advantage of human genome sequence, which is public knowledge. Of great importance, the construction of efficient delivery system may also be addressed for a successful beginning.

Even though novel gene editing technologies are arising, RNAi-based technologies seem to be safer due to its transient effect, which in part is similar to the traditional drugs. Finally, it definitely emerged to be established as a new pharmacologic class of drugs. Consequently, in the next years it is possible to assume that other RNAi-based medicines will come to clinics faster, bringing the progress of years of research to the society.

\section{References}

1. Fire A, Xu S, Montgomery MK, Kostas SA, Driver SE, et al. (1998) Potent and specific genetic interference by double-stranded RNA in Caenorhabditis elegans. Nature 391(6669): 806-811.

2. Elbashir S, Harborth J, Lendeckel W, Yalcin A, Weber K, et al. (2001) Duplexes of 21-nucleotide RNAs mediate RNA interference in cultured mammalian cells. Nature 411(6836): 494-498.

3. Chendrimada T, Gregory RI, Kumaraswamy E, Norman J, Cooch N, et al. (2005) TRBP recruits the dicer complex to Ago2 for microRNA processing and gene silencing. Nature 436(7051): 740-744.

4. Rana TM (2007) Illuminating the silence: understanding the structure and function of small RNAs. Nat Rev Mol Cell Biol 8(1): 23-36.

5. Finan C, Gaulton A, Kruger FA, Lumbers RT, Shah T, et al. (2017) The druggable genome and support for target identification and validation in drug development. Sci Transl Med 9(383): 1-15.

6. Nam J, Won N, Bang J, Jin H, Park J, et al. (2013) Surface engineering of inorganic nanoparticles for imaging and therapy. Advanced Drug Delivery Review 65(5): 622-648.

7. Mishra DK, Balekar N, Mishra PK (2017) Nanoengineered strategies for siRNA delivery: from target assessment to cancer therapeutic efficacy. Drug Deliv Transl Res 7(2): 346-358.

8. Lee SJ, Kim MJ, Kwon IC, Roberts TM (2016) Delivery strategies and potential targets for siRNA in major cancer types. Adv Drug Deliv Rev 104: $2-15$

9. Kaushal, GP, Shah SV (2014) Challenges and Advances in the Treatment of AKI. J Am Soc Nephrol 25(5): 877-883.

10. Benoit SW, Devarajan P (2018) Acute kidney injury: emerging pharmacotherapies in current clinical trials. Pediatr Nephrol 33(5): 779-787.

11. Solano ECR, Kornbrust DJ, Beaudry A, Foy JWD, David Schneider DJ, et al. (2014) Toxicological and Pharmacokinetic Properties of QPI-1007, a Chemically Modified Synthetic- siRNA Targeting Caspase 2 mRNA, Following Intravitreal Injection. Nucleic Acid Therapeutics 24(4): 258266.

12. Moreno-Montañés, J, Bleau AM, Jimenez AI (2018) Tivanisiran, a novel siRNA for the treatment of dry eye disease. Expert Opinion on Investigational Drugs (4): 421-426.

13. Springer AD, Dowdy SF (2018) GalNAc-siRNA Conjugates: Leading the Way for Delivery of RNAi Therapeutics. Nucleic Acid Therapeutics 28(3): 109-118

14. Machin N, Ragni M (2018) Na investigation RNAi therapeutic targeting antithrombin for the treatment of hemophilia A and B. Journal of Blood Medicine: 9: 135-140.

15. German CA, Shapiro MD (2019) Small Interfering RNA Therapeutic Inclisiran: A new approach to targeting PCSK9. Bio Drugs 34: 1-9.

16. Janas MM, Zlatev I, Liu J, Jiang Y, Barros SA, et al. (2019) Safety evaluation of 2'-deoxy-2'-fluoro nucleotides in GalNAc-siRNA conjugates. Nucleic Acids Research 47(7): 3306-3320.

17. Liebow A, Li X, Racie T, Hettinger J, Bettencourt BR, et al. (2017) An Investigational RNAi Therapeutic Targeting Glycolate Oxidase Reduces Oxalate Production in Models of Primary Hyperoxaluria. J Am Soc Nephrol 28(2): 494-503.

18. Sardh E, Harper P, Balwani M, Stein P, Rees, et al. (2019) Phase 1 Tria of an RNA Interference Therapy for Acute Intermittent Porphyria. N Engl J Med 380: 549-58. 
19. Scott LJ (2020) Givosiran: First Approval. Drugs 70: 335-339.

20. Adams D, Gonzalez-Duarte A, O'Riordan WD, Yang CC, Ueda M Kristen AV, et al. (2018) Patisiran, an RNAi Therapeutic, for Hereditary Transthyretin Amyloidosis. The New England Journal of Medicine 379: 11-21.

21. Akinc A, Maier MA, Manoharan M, Fitzgerald K, Jayaraman M, et al. (2019) The Onpattro story and the clinical translation of nanomedicines containing nucleic acid-based drugs. Nature Nanotechnology 14: 1084-1087.
22. Alnylam Pharmaceuticals (2020)

23. ClinicalTrials.gov. Bethesda (MD): National Library of Medicine (US)

This work is licensed under Creative Commons Attribution 4.0 License

DOI: 10.19080/CTBEB.2020.19.556022 